\title{
The Design of a Digital Behaviour Change Intervention for Third-Level Student Illicit Substance Use: A Persona Building Approach
}

\author{
Samantha Dick \\ University College Cork \\ samantha.dick@ucc.ie \\ Martin P. Davoren \\ University College Cork; \\ Sexual Health Centre, Cork \\ martindavoren@sexualhealthcen \\ $\underline{\text { tre.com }}$ \\ Michael Byrne \\ University College Cork \\ m.byrne@ucc.ie
}

\author{
Ciara Heavin \\ University College Cork \\ c.heavin@ucc.ie
}

Samantha Dockray

University College Cork

s.dockray@ucc.ie

\author{
Vasilis Vasiliou \\ University College Cork \\ v.vasiliou@ucc.ie \\ Conor Linehan \\ University College Cork \\ conor.linehan@ucc.ie
}

\begin{abstract}
Illicit substance use among third-level students is an issue of increasing concern. Digital behavioural change interventions have been developed to target this population, but reports of their effectiveness are mixed. The importance of end-user involvement in digital intervention development has been well established, but it appears that many interventions in this area did not engage end-users during development. This absence may have affected engagement, undermining their potential effectiveness. This paper describes the process and contributions of a persona-building approach in the development of a digital behaviour change intervention tailored to the needs of third-level students. Nine exploratory persona-building workshops were carried out with 31 students, and 7 project team members to develop personas for heavy, occasional and nonsubstance using third-level students. Early analysis has identified five archetypes which will contribute to the design of an acceptable and user-friendly intervention, and to the identification of targeted behavioural change techniques.
\end{abstract}

\section{Introduction}

Digital devices have been used in the delivery of many different interventions for various health behaviours, including alcohol consumption, tobacco smoking, and illicit substance use [1-6]. Third-level students are a particularly underserved population in this area of research $[7,8]$, despite being vulnerable to the use of illicit substances [8,9]. We define third-level students as individuals who have completed statutory formal education (such as secondary/high-school) and are pursuing further education in an institution such as a college, university or institute of technology. Internationally, just under a quarter of third-level students report current use of an illicit substance [7, 911]. The harms from illicit substance use are broad; affecting both mental and physical health [7, 12-16]. In addition, third-level students are at risk of many academic-related negative outcomes including missing classes [14] and receiving lower grades [12], an increase in drop-out rates [17-20], delayed graduation [18], expulsion or suspension [12], and failure to attain a degree [21].

Several digital interventions for this population have been developed, but reports of their effects are mixed, with some producing no significant effects [22-24], and many others achieving only modest reductions in harm [25-29]. Further, many of these interventions have reported problems with user engagement [23, 24, 27]. A recent review of the User Centred Design (UCD) practices during the design, development and evaluation of such interventions found that published interventions reported very little information on the level of user involvement [30]. It is plausible that a lack of user involvement has resulted in a failure to engage users particularly in the early analysis and design stages, and has thereby undermined the potential effectiveness of these interventions [31]. 
There is a considerable body of evidence highlighting the importance of end-user involvement in the design of digital interventions [31-33], but the application of this use is not evident in the published reports of these interventions. The UCD process aims to analyse the needs, desires and limitations of the end user, in order to capture the assumptions about user behaviour and embody them in the intervention prototypes [33]. Persona building is one aspect of the UCD methodology which attempts to capture user's expectations, prior experiences and anticipated behaviours, leading to an understanding of how they think, feel and behave [33]. This understanding enables interventionists to identify with, and to meaningfully communicate with the target user [33]. By incorporating specific user profiles tailored to the population, interventions can increase user motivation through carefully selected behaviour change techniques, to maximize the formation of targeted behaviour changes $[34,35]$. Persona's move us past "users" to thinking about designing for real people, structuring usercentred thinking, and allow for the prioritisation of user needs when faced with digital design decisions [36]. Despite its benefits, this methodology may be underutilised [37]. Ensuring that the entire development team are involved in the creation of personas with endusers can contribute to solving this issue [38].

The "My Understanding of Substance-use Experiences" (MiUSE) project aims to develop an information systems (IS) artefact, a digital harm reduction intervention, for illicit substance use in thirdlevel students which is usable and acceptable to this population. This will be achieved by embracing an interdisciplinary approach, including Information Systems, Health Psychology, and Public Health, to intervention design, development and evaluation [39].
Phase 1 outlined in this article presents a systematic UCD approach allowing the user to inform all stages of the design and development; including the content (i.e. behavioural change intervention), design (i.e. IS artefact features), implementation, and evaluation. The persona building approach will be used to develop archetypes that represent the target users of this digital intervention to guide IS artefact design decisions. To ensure full utilisation of the persona data, the archetypes developed from the personas will serve as a useful proxy when identifying and tailoring the behavioural change techniques, using the Behaviour Change Wheel framework (BCW) [40]. The $\mathrm{BCW}$ is a multi-stage process-based guide that employs a systematic evidence synthesis to understand the behavioural problem and identify appropriate behavioural change techniques (BCTs) [41]. The description and analysis of how BCTs are selected and implemented in a digital intervention, providing information about the theoretical basis, functionality and software interface, is often absent from the relevant literature. Thus, the use of the $\mathrm{BCW}$ is becoming an important ally for any behaviour change system developer [42]. It forms the basis of the intervention development, identifying intervention functions such as education, persuasion, incentivisation or restrictions [40], thereby linking specific therapeutic mechanisms to treatment outcomes [43].

\section{Methodology}

During phase one of the development of this IS artefact, a number of exploratory workshops were carried out with student participants and an expert group of academic and clinical staff. Further evaluative workshops will be carried out during phase two of the

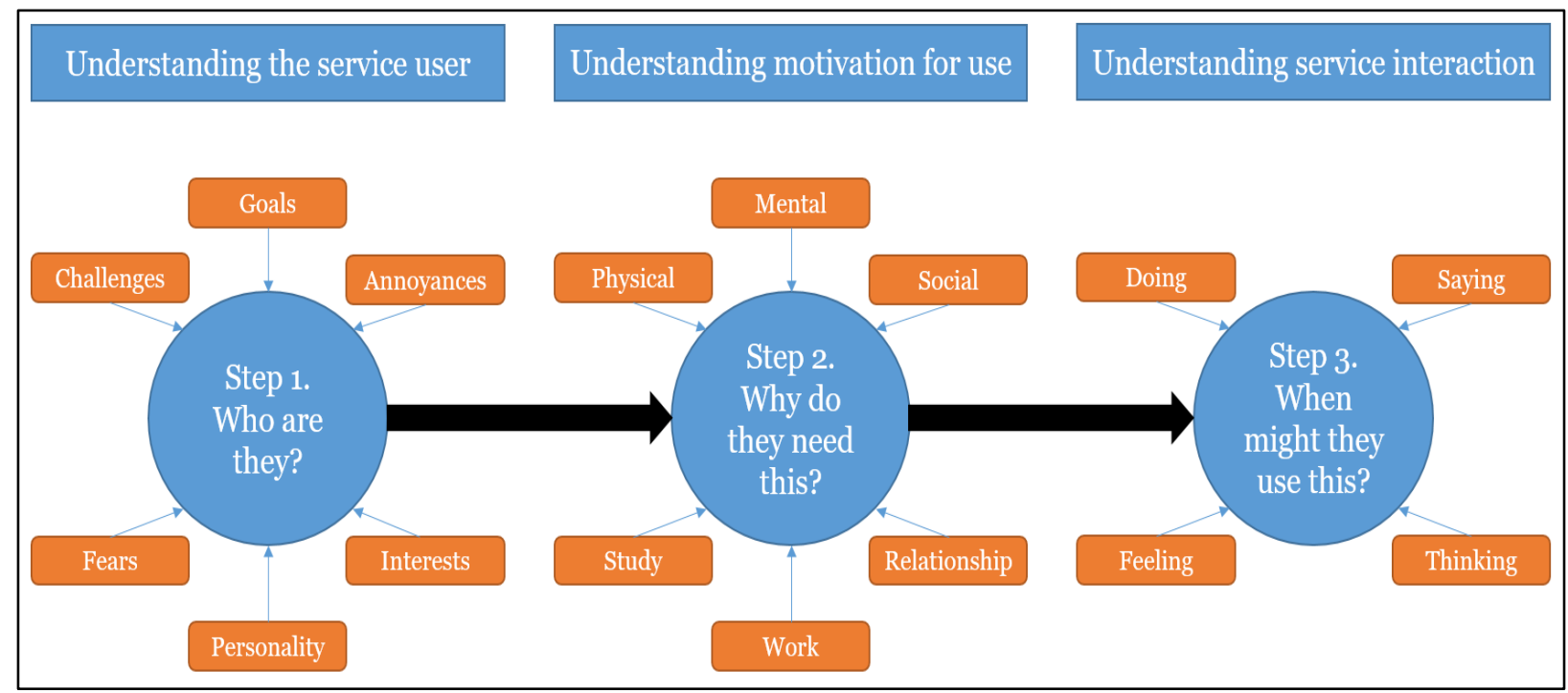

Figure 1. The three-step workshop process 
development in order to inform the intervention design. This research study was approved by the Social Research Ethics Committee and University College Cork.

During phase one, exploratory workshops were conducted with university students and the project team. The workshops were advertised in December 2017 through in-class presentations delivered by the research team, and via the Student's Union social media accounts, which allowed students to sign up for the workshops. A total of 112 students expressed an interest in the workshops and they were contacted separately to outline further details of the workshops. Following this, 31 students responded and gave consent to participate in the workshops.

\subsection{Exploratory workshops}

A series of 8 workshops were conducted with 31 students between December 2017 and February 2018 to build an understanding of the service user, their motivations for use, and potential service interaction scenarios, using a UCD persona building approach [33]. This was achieved in a three-step process as illustrated in Figure 1.

Step 1: Developing an understanding of the service user: workshop participants were presented with three fictional users; a) Martin, who has never used drugs, b) Jane, who uses drugs occasionally, and c) Stephen, who uses drugs regularly. Participants were provided with a persona building template and asked to build up each persona based on their 1. Demographic information, such as age, living arrangements, and relationship status, 2. Personality traits, such as anxiety levels and happiness, 3. Interests, including TV and music interests, phone apps and spare time activities, 4 . Money spending behaviour, and what they would do with a financial surplus, 5. Day to day challenges and annoyances, 6. Biggest goals and fears for the next 12 months, 7. Typical routine for a night out.

Step 2: Understanding the motivation for service use: workshop participants were asked to consider the wider aspects of their persona's life and how their relationship with substances might interfere with areas of their life including; mental and physical health, relationships, and work or study.

Step 3: Understanding the service interaction scenarios: workshop participants used the format of a short story to describe the events leading up to the recognition of a need or concern of their persona. Participants were encouraged to use an empathy map format when telling their story, describing what their persona is doing, saying, thinking and feeling.

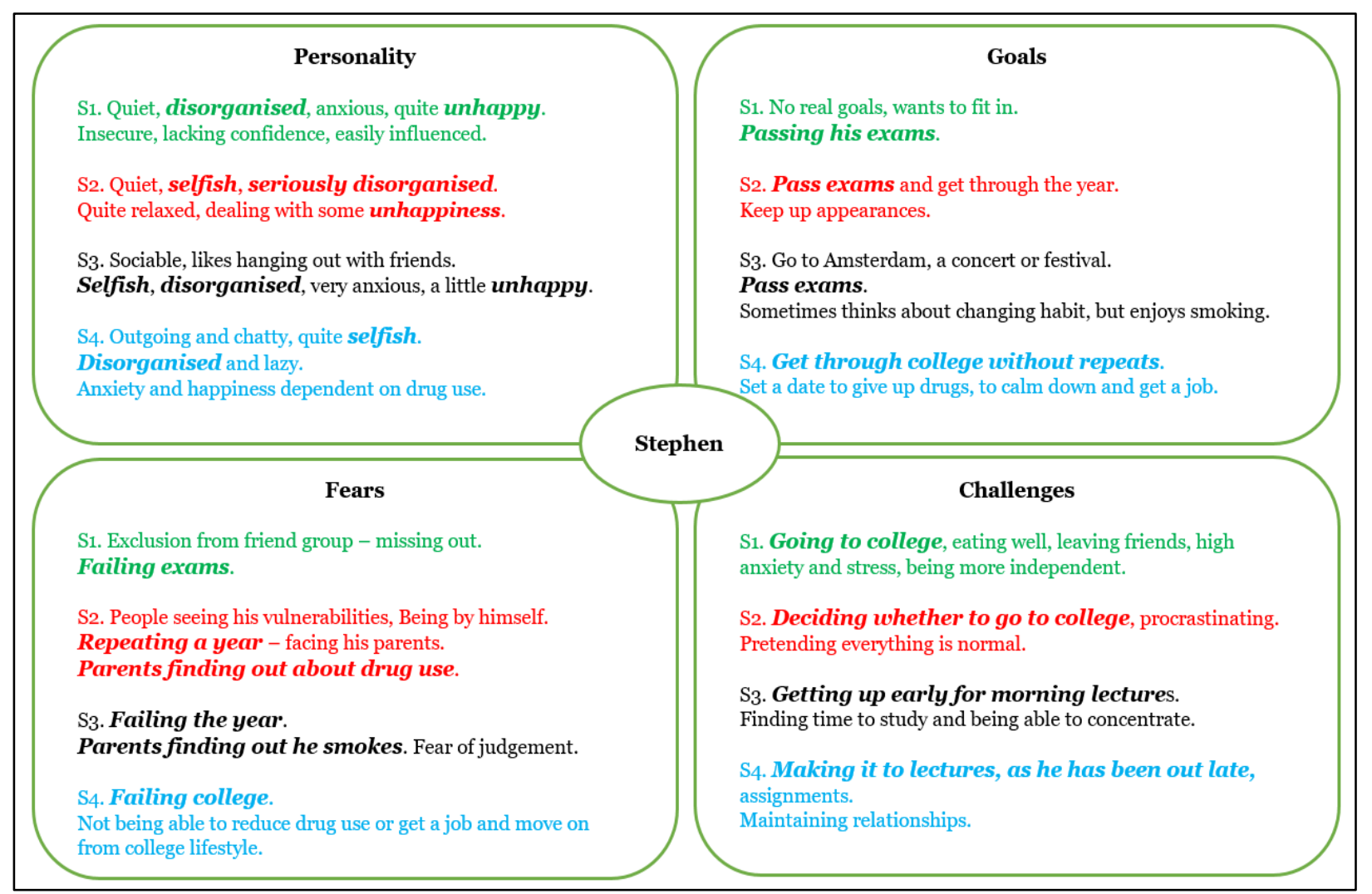

Figure 2. Persona mapping sample of "Stephens" 
In order to strengthen the rigour of the process, an additional workshop was conducted with the project team ("Expert Group"). The research team consists of academic and clinical staff who both have regular contact with students and possess a unique insight of their behaviours and needs. A half-day workshop was held in February 2019, where the team built personas for Martin, Jane, and Stephen, in an identical process to the student workshops.

\subsection{Data analysis}

The persona templates and participant notes were digitalised, and the workshop recordings were transcribed verbatim. Digital recordings were deleted after transcription. The notes, templates and audio recording from step one of the workshop process were combined to create detailed persona descriptions. Two members of the research team undertook a comprehensive open coding process to identify themes from the personas. These themes were mapped onto a ten-item matrix, which highlighted characteristics and patterns between the personas. The matrix expanded on the persona template and included; 1. Demographic information, such as age, course of study, living arrangements, 2. Personality traits, such as anxiety levels and happiness, 3. Interests, including TV and music interests, phone apps etc., 4. Behavioural patterns, such as money spending and spare-time activities 6. Goals and fears for the next 12 months, 7. Day-to-day challenges, 8. Annoyances, and 10. A typical social routine. Figure 2 presents a sample of the mapping process for the "Stephens," and the emergence of common themes between each persona.

Once this mapping was complete, a half-day analysis workshop took place with the entire project team in March 2019. The team worked in groups to identify similarities and differences between the characteristics of each persona. This was followed by an in-depth group discussion of the identified characteristics until a consensus was reached on the emerging archetypes. The unique characteristics of each archetype will be used to identify behavioural change components which can be targeted to the end-users, using the $\mathrm{BCW}$ framework [40].

\section{Preliminary analysis}

Preliminary analysis of the first step of the exploratory workshop data has identified five emerging archetypes, who vary in their level of substance use, and their needs, desires and limitations. These archetypes will be used as initial representatives of the target student population when selecting and tailoring the behavioural change components of the digital intervention.

\subsection{Heavy substance users - the "Approval Seeker" and the "Pleasure Seeker"}

"He smokes joints as if it was nothing, he's so used to it... just before heading out, they all drop bombs of $M D M A "(W 1)$.

Five heavy-using personas were developed over the course of the workshops. They are likely be living with friends in a shared rental house, "where there's no [campus] security" (W1), post-first year "into the run of things a bit more, settled" (W4), and enrolled in a course with a low number of contact hours. They are likely to be very disorganised and quite selfish, as well as dealing with anxiety and unhappiness. In addition, relationships with family, peers and romantic partners are likely to be strained. Goals are short-term and predominantly academic based, "his first goal is just to pass his exams, and that's the furthest away goal he has" (W2). Prominent challenges for them are mainly academic, including procrastination "getting up early in the morning, because he was up the night before" (W5), and maintaining a pretense of normality "he goes to the gym... to maintain an aspect of normality" (W4). Identified fears are academic failure, social exclusion or judgement from others "they know that people don't approve" (W4), families discovering substance use "more of a fear than being caught by the police" (W4), and exposing vulnerabilities to peers.

In addition to the common characteristics, several unique characteristics emerged, identifying two distinct archetypes. The first, the "Approval Seeker," likely has a quiet personality, and uses substances as an instrument in social situations "social doping" (W5), or as a way of fitting in "he's trying to be cool, going with the motions" (W2). The second, the "Pleasure Seeker," is outgoing and prioritises their substance use over other aspects of their lives. Despite the heavy use of these archetypes, several participants identified potential triggers for change regarding their substance use, "he wants to fix it, but also wants to smoke up, he's in between" (W5). "After a big night out... realisation, regret, was it worth it?" (W4); "In the back of his head he knows that he needs to cut down on his drug taking over the next year" (W1), "he knows that he's conforming a little bit and that he needs to branch out from the lads... he's afraid to be left out" (W2).

\subsection{Non-substance users - the "Health Enthusiast"}


"Takes his health and fitness so seriously, that's why he doesn't do drugs" (W2).

Two abstaining personas were developed over the course of the workshops. This persona is likely to have a lot of routine in their life, likely involved in a sport or hobby with a strong health or fitness focus. They are organised, considerate and generally happy, with several well-focused, future-oriented goals. Major fears include academic or professional failure "finds the academic thing a bit challenging... prioritising sport over lectures" (W7), and not having enough time for hobbies. Their social routine is likely to be alcohol oriented, involving heavy binge-sessions and "competitive drinking" (W7). He is often exposed to substance using peers, and gets annoyed by their use "he's still living with college friends, he's annoyed that they're not getting their stuff together" (W2). No unique characteristics were identified between the two abstaining personas, thereby forming one distinct archetype, the "Health Enthusiast".

\subsection{Occasional substance users - the "High Achiever" and the "Social Butterfly"}

"I think she's just taking drugs because everyone else is taking them" (W2).

Four occasional using personas were developed over the course of the workshops with many similarities. They are likely to be very confident and social, mostly content with life "she's doing alright" (W6). They are likely to have stable, positive relationships with others and be quite appearance orientated, with a strong social life "she likes to be seen out" (W2). Goals are both academic and social, representing milestone events; such as going on a holiday with friends or going abroad in the summer. Balancing all aspects of life are likely to be a challenge, they are competitive and performative. Fears include academic failure and the disappointment or disapproval of parents "she's not a drug user in her mind, she wouldn't want the stress and disappointment of her parents" (W6). Substance use is likely to occur in social settings with friends, and may be influenced by the social context "if she was at a house party and it was easily available to her. She wouldn't be actively seeking it" (W3). They may engage in occasional social marijuana smoking, or the sharing of MDMA with friends during a night out.

Several unique characteristics emerged between the occasional user personas, representing two distinct archetypes. The "High Achiever" is quite disorganised and anxious but very future-focused and wanting to do well in college "she wants a $1 H$ " (W6). The "Social Butterfly" is more relaxed and organised, and less concerned about academic success, "she's in college to have a good time” (W3). Figure 3 presents an overview of the five emerging archetypes.

\section{Discussion}

This study utilised a persona-building methodology [33] to develop archetypes representing the target users of a digital behaviour change intervention for third-level student illicit substance use. Initial analysis of the persona workshop data has uncovered five distinct

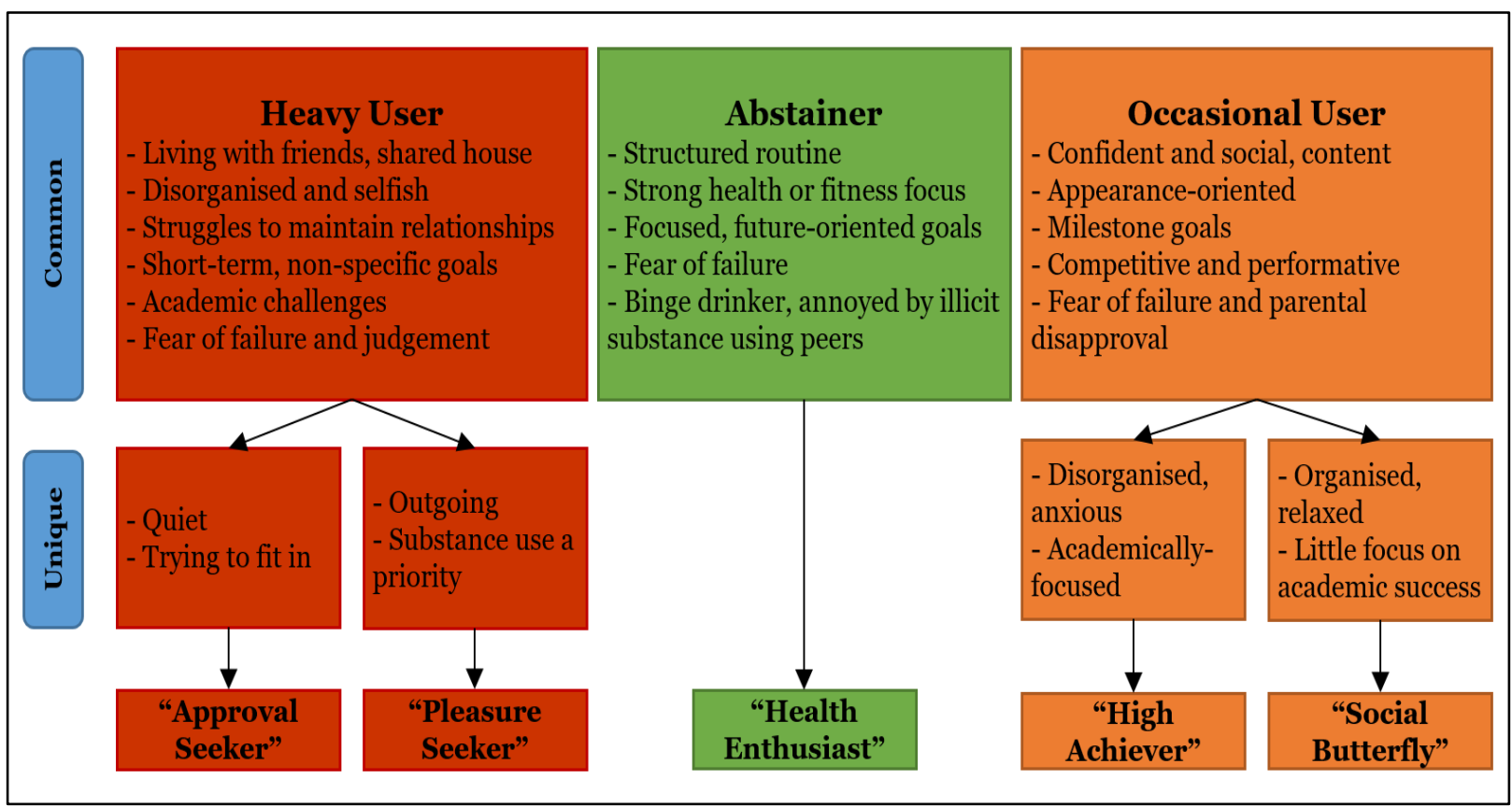

Figure 3. Overview of emerging five user archetypes 
archetypes, differing in their level of interaction with substances, and their personal motivations for changing and reducing harm from illicit substance use. Each archetype has a number of unique intervention delivery targets, which will be used to ensure that the intervention is relevant and acceptable to them. Further, the archetypes can be used in the tailoring and personalisation of the intervention content. This early analysis provides an indication of the potential intervention components which may be effective for the users of this intervention.

The "Pleasure Seeker" is likely to use substances because they genuinely enjoy the effects of them. This persona will possibly be more difficult to engage in an intervention, but may respond to educational components targeted toward increasing knowledge of the impact of substance use on their academic and relationship successes [7]. The "Approval Seeker" is likely to be using substances as part of a wider social group, in order to fit in, and may derive less enjoyment from their use. This persona could be targeted with a training component, which would aim to improve their resilience and ability to resist peer pressures resulting in substance use [24].

The "Health Enthusiast" is likely to have a hobby or sport which takes up a significant proportion of their time. Although non-using students make up the majority of the student population, and will not be the primary target user of this intervention, it will still be important to include a tailored component for this persona. Involvement in sport or with hobbies is a protective factor against illicit substance use [44, 45], but during the changes of transitioning to university life, some may lose interest in such activities. Therefore, we would postulate that some non-users are likely to be in a precontemplative stage and could benefit from early, preventative intervention in the form of education to increase knowledge of substance use impacts, or modelling with the presentation of an aspirational figure. Further, a non-using student is likely to be exposed to a substance-using student during their university years, so there may be an opportunity for a skills-training component in dealing with a substanceusing friend.

The occasional substance user is likely to represent the target user of the digital intervention. The "High Achiever" may be the easier of the two to target with this intervention, and tailored behavioural change components could include education components to promote awareness of the academic consequences of substance use, and training components to encourage resistance to peer-pressures of substance use [24]. The "Social Butterfly," although less academically focused, still exhibits behaviours which could be targeted in an intervention. For example, the performative and appearance-oriented aspects of their life provide an opportunity for a persuasion component to deliver personalised feedback on social norms of substance use [7], or a modelling component with an aspirational figure targeting the physical consequences of substance use.

\section{Future work}

The identification of potential user archetypes, as well as their unique characteristics, needs and goals has provided a description of the persuasion context where the digital features of the intervention can be developed to trigger cognitive and emotional changes in the target users. By gaining a comprehensive understanding of the archetypes and the target behaviours, we are better placed to identify and test particular behaviour change features and combinations in the IS artefact design [4648]. Through the BCW framework, specific latent motivations, opportunities and capabilities will be identified and matched to the user archetypes.

Further, in providing intervention content that is relatable to the user, engagement will be improved, thereby increasing its potential effectiveness [31-33]. Analysis of the data collected in steps 2 and 3 of the workshops will allow us to explore the motivation for service use and develop an understanding of the service interaction scenarios. During the second phase of the intervention development, exploratory workshops will be conducted with students. These will include concept testing, role playing, $\mathrm{A} / \mathrm{B}$ testing and usability testing. Student participants will be recruited for these workshops over a 12-month development phase. Following on from the UCD analysis of the data, we will conduct a directed content analysis [49] to identify themes that reflect students' capabilities, opportunities, and motivations for changing substance use behaviour. The themes identified from the workshops will be mapped onto the $\mathrm{BCW}$ in order to identify the most salient behavioural change techniques for each identified archetype.

\section{Conclusion}

The UCD process has allowed us to develop an indepth understanding of the needs, desires and limitations of potential end users of this intervention. The insights gathered both from student participants and the expert group will contribute to an intervention that is relevant and acceptable to the end user, utilising behavioural change components and IS artefact features which are tailored to the unique characteristics of thirdlevel students in an Irish context. Further analysis will allow us to make evidence-based decisions about the 
content of our intervention, resulting in the development of an intervention that is familiar and acceptable to our student population.

We attempted to improve generalisability by conducting 8 persona building workshops with students from various academic disciplines and with the Student's Union Officers. The Student Union Officers have a unique insight, given that they are students themselves, and also engage in daily interactions with the wider student body. Further, the additional "expert group" workshop drew on the expertise of academics and student health clinicians who have considerable experience of working with students. This approach has provided a deep understanding of the characteristics of a student in an Irish third-level context.

\section{Acknowledgements}

With thanks to Dr Damien Organ for the design and facilitation of the persona-building workshops. The MiUSE project is funded by the Student Charges and Fees Forum at University College Cork.

\section{References}

[1] Witkiewitz K, Desai SA, Bowen S, Leigh BC, Kirouac M, Larimer ME. Development and evaluation of a mobile intervention for heavy drinking and smoking among college students. Psychology of Addictive Behaviours. 2014;28(3):639-50. DOI: 10.1037/a0034747

[2] Bendtsen P, Bendtsen M, Karlsson N, White I, McCambridge J. Online Alcohol Assessment and Feedback for Hazardous and Harmful Drinkers: findings From the AMADEUS-2 Randomized Controlled Trial of Routine Practice in Swedish Universities. Journal of Medical Internet Research. 2015;17(7):e170. DOI: 10.2196/jmir.4020

[3] Geisner IM, Varvil-Weld L, Mittmann AJ, Mallett K, Turrisi R. Brief web-based intervention for college students with comorbid risky alcohol use and depressed mood: does it work and for whom? Addictive Behaviors. 2015;42:36-43. DOI: 10.1016/j.addbeh.2014.10.030

[4] Bewick B, Trusler K, Mulhern B, Barkham M, Hill A. The feasibility and effectiveness of a web-based personalised feedback and social norms alcohol intervention in UK university students: a randomised control trial. Addictive Behaviors. 2008;33(9):1192-8. DOI: 10.1016/j.addbeh.2008.05.002

[5] Bewick BM, West R, Gill J, O'May F, Mulhern B, Barkham M, et al. Providing web-based feedback and social norms information to reduce student alcohol intake: a multisite investigation. Journal of Medical Internet Research. 2010;12(5):e59. DOI: 10.2196/jmir.1461
[6] McCambridge J, Bendtsen M, Karlsson N, White IR, Nilsen P, Bendtsen P. Alcohol assessment and feedback by email for university students: main findings from a randomised controlled trial. The British Journal of Psychiatry. 2013;203(5):334-40. DOI: 10.1192/bjp.bp.113.128660

[7] Bennett TH, Holloway KR. Drug misuse among university students in the UK: implications for prevention. Substance Use \& Misuse. 2014;49(4):448-55. DOI: $10.3109 / 10826084.2013 .846378$

[8] Bennett TH, Holloway KR. Drug use among college and university students: findings from a national survey. J Subst Use. 2015;20(1):50-5. DOI: 10.3109/14659891.2013.878762

[9] Schulenberg JE, Johnson LD, O'Malley PM, Bachman JG, Miech RA, Patrick ME. Monitoring the Future national survey results on drug use, 1975-2016: College Students \& Adults Ages 19-55. Ann Arbor: Institute for Social Research, The University of Michigan; 2017. Available from: http://www.monitoringthefuture.org//pubs/monographs/mtfvol2_2016.pdf

[10] Substance Abuse and Mental Health Services Administration. Results from the 2013 National Survey on Drug Use and Health: Summary of national findings. Rockville, MD: Substance Abuse and Mental Health Services Administration, Center for Behavioral Health Statistics and Quality; 2014. Available from: https://www.samhsa.gov/data/sites/default/files/NSDUHresul tsPDFWHTML2013/Web/NSDUHresults2013.pdf

[11] Cahill E, Byrne M. Alcohol and drug use in students attending a student health centre. Irish Medical Journal. 2010;103(8):230-3.

[12] Palmer RS, McMahon TJ, Moreggi DI, Rounsaville BJ, Ball SA. College Student Drug Use: Patterns, Concerns, Consequences, and Interest in Intervention. J Coll Student Dev. 2012;53(1):124-32. DOI: 10.1353/csd.2012.0014

[13] Juan W, Jian-Xiong D, Lan G, Yuan H, Xue G, Jing-Hui $\mathrm{H}$, et al. Non-medical use of psychoactive drugs in relation to suicide tendencies among Chinese adolescents. Addictive Behaviors. 2015;51:31-7. DOI: 10.1016/j.addbeh.2015.07.003

[14] Kunst LE, Gebhardt WA. Prevalence and Psychosocial Correlates of Party-Drug Use and Associated Problems among University Students in the Netherlands. Substance Use \& Misuse. 2018;53(12):2077-88. DOI: $10.1080 / 10826084.2018 .1455700$

[15] United Nations Office on Drugs and Crime. World Drug Report 2018. Vienna, Austria: United Nations publication, Sales No. E.18.XI.9; 2018. Available from: https://www.unodc.org/wdr2018/prelaunch/WDR18_Booklet 1_EXSUM.pdf 
[16] Skidmore CR, Kaufman EA, Crowell SE. Substance use among college students. Child and Adolescent Psychiatric Clinics. 2016;25(4):735-53. DOI: 10.1016/j.chc.2016.06.004

[17] Arria AM, Caldeira KM, Bugbee BA, Vincent K, O'Grady KE. The academic opportunity costs of substance use during college. College Park, MD: Center on Young Adult Health and Development, University of Maryland School of Public Health; 2013. Available from: www.cls.umd.edu/docs/AcadOppCosts.pdf

[18] Suerken CK, Reboussin BA, Egan KL, Sutfin EL, Wagoner KG, Spangler J, et al. Marijuana use trajectories and academic outcomes among college students. Drug and Alcohol Dependence. 2016;162:137-45. DOI: 10.1016/j.drugalcdep.2016.02.041

[19] Jeynes WH. The relationship between the consumption of various drugs by adolescents and their academic achievement. Am J Drug Alcohol Ab. 2002;28(1):15-35. DOI: 10.1081/Ada-120001279

[20] European Monitoring Centre for Drugs and Drug Addiction. Health and social responses to drug problems: a European guide. Luxembourg: Publications Office of the European Union; 2017. Available from: http://www.emcdda.europa.eu/system/files/publications/6343 /TI_PUBPDF_TD0117699ENN_PDFWEB_2017100915364 9.pdf

[21] Horwood LJ, Fergusson DM, Hayatbakhsh MR, Najman JM, Coffey C, Patton GC, et al. Cannabis use and educational achievement: Findings from three Australasian cohort studies. Drug and Alcohol Dependence. 2010;110(3):247-53. DOI: 10.1016/j.drugalcdep.2010.03.008

[22] Cameron D, Epton T, Norman P, Sheeran P, Harris PR, Webb TL, et al. A theory-based online health behaviour intervention for new university students (U@Uni:LifeGuide): results from a repeat randomized controlled trial. Trials. 2015;16(1):555. DOI: 10.1186/s13063-015-1092-4

[23] Epton T, Norman P, Dadzie AS, Harris PR, Webb TL, Sheeran P, et al. A theory-based online health behaviour intervention for new university students (U@Uni): results from a randomised controlled trial. BMC Public Health. 2014;14(1):563. DOI: 10.1186/1471-2458-14-563

[24] Haug S, Paz Castro R, Meyer C, Filler A, Kowatsch T, Schaub MP. A Mobile Phone-Based Life Skills Training Program for Substance Use Prevention Among Adolescents: Pre-Post Study on the Acceptance and Potential Effectiveness of the Program, Ready4life. JMIR mHealth and uHealth. 2017;5(10):e143. DOI: 10.2196/mhealth.8474

[25] Lee CM, Neighbors C, Kilmer JR, Larimer ME. A brief, web-based personalized feedback selective intervention for college student marijuana use: a randomized clinical trial. Psychol Addict Behav. 2010;24(2):265-73. DOI: 10.1037/a0018859
[26] Elliott JC, Carey KB. Correcting exaggerated marijuana use norms among college abstainers: a preliminary test of a preventive intervention. Journal of Studies on Alcohol and Drugs. 2012;73(6):976-80. DOI: 10.15288/jsad.2012.73.976

[27] Elliott JC, Carey KB, Vanable PA. A preliminary evaluation of a web-based intervention for college marijuana use. Psychol Addict Behav. 2014;28(1):288-93. DOI: 10.1037/a0034995

[28] Palfai TP, Saitz R, Winter M, Brown TA, Kypri K, Goodness TM, et al. Web-based screening and brief intervention for student marijuana use in a university health center: pilot study to examine the implementation of eCHECKUP TO GO in different contexts. Addictive Behaviors. 2014;39(9):1346-52. DOI: 10.1016/j.addbeh.2014.04.025

[29] Christoff Ade O, Boerngen-Lacerda R. Reducing substance involvement in college students: a three-arm parallel-group randomized controlled trial of a computerbased intervention. Addictive Behaviors. 2015;45:164-71. DOI: 10.1016/j.addbeh.2015.01.019

[30] Organ D, Dick S, Hurley C, Heavin C, Linehan C, Dockray S, et al., A Systematic Review of User-Centred Design Practices in Illicit Substance Use Interventions for Higher Education Students. 25th European Conference on Information Systems - Beyond Digitization: Facets of SocioTechnical Change; 2018; Portsmouth, UK.

[31] McCurdie T, Taneva S, Casselman M, Yeung M, McDaniel C, Ho W, et al. mHealth consumer apps: the case for user-centered design. Biomedical Instrumentation \& Technology. 2012;46(s2):49-56.

[32] van Gemert-Pijnen JE, Nijland N, van Limburg M, Ossebaard HC, Kelders SM, Eysenbach G, et al. A holistic framework to improve the uptake and impact of eHealth technologies. Journal of Medical Internet Research. 2011;13(4):e111. DOI: 10.2196/jmir.1672

[33] LeRouge C, Ma J, Sneha S, Tolle K. User profiles and personas in the design and development of consumer health technologies. International Journal of Medical Informatics. 2013;82(11):e251-e68.

[34] Kelders SM, Oinas-Kukkonen H, Oörni A, van GemertPijnen JEWC. Health Behavior Change Support Systems as a research discipline; A viewpoint. International Journal of Medical Informatics. 2016;96:3-10. https://doi.org/10.1016/j.ijmedinf.2016.06.022

[35] Oinas-Kukkonen H, Harjumaa M. Persuasive systems design: Key issues, process model, and system features. Communications of the Association for Information Systems. 2009;24(1):28. 
[36] Ward JL, Persona development and use, or, how to make imaginary people work for you. 2010 Library Assessment Conference; 2010; Baltimore, Maryland.

[37] Friess E, Personas and decision making in the design process: An ethnographic case study. Conference on Human Factors in Computing Systems - Proceedings; 2012; Austin, Texas. 10.1145/2207676.2208572

[38] Howard TW. Are personas really usable? Communication Design Quarterly Review. 2015;3(2):20-6.

[39] Mummah SA, Robinson TN, King AC, Gardner CD, Sutton S. IDEAS (Integrate, Design, Assess, and Share): A Framework and Toolkit of Strategies for the Development of More Effective Digital Interventions to Change Health Behavior. Journal of Medical Internet Research. 2016;18(12):e317-e. 10.2196/jmir.5927

[40] Michie S, Van Stralen MM, West R. The behaviour change wheel: a new method for characterising and designing behaviour change interventions. Implementation Science. 2011;6(1):42.

[41] Michie S, Richardson M, Johnston M, Abraham C, Francis J, Hardeman W, et al. The behavior change technique taxonomy (v1) of 93 hierarchically clustered techniques: building an international consensus for the reporting of behavior change interventions. Annals of behavioral medicine. 2013;46(1):81-95.

[42] Lehto T, Oinas-Kukkonen H. Persuasive Features in Web-Based Alcohol and Smoking Interventions: A Systematic Review of the Literature. Journal of Medical Internet Research. 2011;13(3):e46. 10.2196/jmir.1559

[43] Michie S, Johnston M. Theories and techniques of behaviour change: Developing a cumulative science of behaviour change. Health Psychology Review. 2012;6(1):1-6. 10.1080/17437199.2012.654964

[44] Kwan M, Bobko S, Faulkner G, Donnelly P, Cairney J. Sport participation and alcohol and illicit drug use in adolescents and young adults: A systematic review of longitudinal studies. Addictive Behaviors. 2014;39(3):497506.

[45] Elder C, Leaver-Dunn D, Wang MQ, Nagy S, Green L. Organized group activity as a protective factor against adolescent substance use. American Journal of Health Behavior. 2000;24(2):108-13.

[46] O'Raghallaigh P, Adam F. A Framework for Designing Digital Health Interventions. Journal of the Midwest Association for Information Systems (JMWAIS). 2017;2017(2, Article 4).

[47] Patrick K, Hekler EB, Estrin D, Mohr DC, Riper H, Crane $\mathrm{D}$, et al. The Pace of Technologic Change: Implications for
Digital Health Behavior Intervention Research. American Journal of Preventive Medicine. 2016;51(5):816-24. https://doi.org/10.1016/j.amepre.2016.05.001

[48] Yardley L, Morrison L, Bradbury K, Muller I. The person-based approach to intervention development: application to digital health-related behavior change interventions. Journal of Medical Internet Research. 2015;17(1):e30-e. 10.2196/jmir.4055

[49] Hsieh H-F, Shannon SE. Three Approaches to Qualitative Content Analysis. Qualitative Health Research. 2005;15(9):1277-88. 10.1177/1049732305276687 